\title{
Análise epidemiológica dos atendimentos da profilaxia antirrábica humana associados a acidentes com gatos
}

[Epidemiological analysis of human anti-rabies prophylaxis associated with accidents with cats]

$$
\text { I.L. Araújol, T.M. Oliveiral }{ }^{1} \text {, S.A. Diniz }{ }^{2} \text {, M.X. Silva }{ }^{2}
$$

${ }^{1}$ Aluno de pós graduação - Universidade Federal de Minas Gerais - EV - Belo Horizonte, MG

${ }^{2}$ Universidade Federal de Minas Gerais - Escola de Veterinária - EV - Belo Horizonte, MG

\section{RESUMO}

Objetivou-se conhecer o perfil epidemiológico do paciente que buscou atendimento antirrábico pósexposição associado a acidentes com gatos domésticos, em Belo Horizonte/MG, no período de 2007 a 2016. Realizou-se uma análise exploratória das fichas de notificação do atendimento antirrábico humano do Sistema de Informação de Agravos de Notificações (Sinan). Nos resultados, observou-se que 37,4\% das pessoas eram adultas do gênero feminino, com idade entre 20 e 59 anos, 88,7\% residentes em área urbana, $26,1 \%$ de etnia branca e apenas $31,7 \%$ dos pacientes buscaram atendimento antirrábico com até 24 horas da exposição ao vírus rábico. Lesões por mordedura ocorreram em $75,6 \%$ dos casos notificados. Quanto às características dos ferimentos, $59,6 \%$ foram superficiais, $62,2 \%$ ocorreram em mãos/pés e $50,1 \%$ foram lesões únicas. Na faixa etária de zero a 10 anos, as regiões anatômicas mãos/pés e cabeça/pescoço/face totalizaram $58,35 \%$. Ressalta-se a necessidade de adoção de ações socioeducativas junto à população, devido ao risco de transmissão de raiva pelo gato, principalmente em áreas em que o vírus rábico circula em populações de morcegos. Sugerem-se melhorias no preenchimento das fichas de notificação do Sinan para melhor compreender o perfil epidemiológico dos pacientes que buscam o atendimento antirrábico e, assim, tornar mais eficaz a gestão desse serviço público.

Palavras-chave: raiva, profilaxia pós-exposição, gatos domésticos

\begin{abstract}
The objective of this study was to know the epidemiological profile of the patient who sought postexposure anti-rabies treatment associated with accidents with domestic cats in Belo Horizonte, Minas Gerais Brazil, from 2007 to 2016. An exploratory analysis of the reports on human rabies of the Notification of Injury Information System was performed. In the results, it was observed that $37.4 \%$ of the individuals were female adults aged 20-59 years, $88.7 \%$ were urban residents, $26.1 \%$ were white, and only $31.7 \%$ sought anti-rabies care within 24 hours of exposure to the rabies virus. Bite lesions occurred in $75.6 \%$. Regarding the type of wound, $59.6 \%$ were superficial; as for the anatomical location, $62.2 \%$ occurred in hands / feet and $50.1 \%$ were single lesions. It is necessary to adopt socio-educational actions among the population, due to the risk of transmission of the rabies by the cat, especially in areas where the rabies virus circulates in bat populations. Improvements in the completion of the SINAN notification sheets are suggested to better understand the epidemiological profile of patients seeking anti-rabies treatment and thus improve the management of this public service.
\end{abstract}

Keywords: rabies, post-exposure prophylaxis, domestic cats

\section{INTRODUÇÃO}

A raiva é uma antropozoonose transmitida aos homens por meio da inoculação do vírus rábico presente na saliva de animais infectados. Afeta o

Recebido em 23 de novembro de 2017

Aceito em 25 de janeiro de 2019

E-mail: isabelaaraujo1234@gmail.com sistema nervoso central (SNC), causando um quadro de encefalite grave. Além disso, é um grave problema de saúde pública em regiões do mundo em que o vírus é presente, pois apresenta alto grau de letalidade e alto custo na assistência preventiva às pessoas que buscam o atendimento 
(Brasil, 2014). Em casos de agressões por animais a seres humanos, a busca por profilaxia antirrábica humana deve ser realizada de forma imediata e deve ser instituída conforme recomendações do Ministério da Saúde (Brasil, 2017). Ao redor do mundo, o cão é o principal transmissor da raiva ao homem. Isso ocorre especialmente em áreas em que as medidas de controle da raiva não foram bem implantadas. Contudo, em países onde as variantes do vírus rábico típicas de cães são controladas e a raiva transmitida por animais silvestres está presente, os gatos domésticos podem desempenhar um papel importante na transmissão do vírus rábico ao homem, já que o instinto de caça faz com que a interação com espécies silvestres possa ocorrer de forma frequente (Bunn, 1991).

O ciclo silvestre da raiva encontra-se em expansão no país; em áreas urbanas, a doença se faz presente por meio da circulação do vírus em morcegos (Wada et al., 2011; Almeida et al., 2015). Morcegos com raiva podem apresentar paralisia de asas ou movimentos desconexos, o que pode aumentar a atração dos gatos e a captura com possível exposição ao vírus (Genaro, 2010).

Segundo o Ministério da Saúde (Brasil, 2018), no período de 2010 a 2017, foram registrados 25 casos de raiva humana, sendo que, em 2014, não houve casos. Nesse período, no ano de 2015 , registrou-se um caso na Paraíba, transmitido por gato, e a identificação da variante era de morcego. Em 2016, foram notificados dois casos de raiva humana, um em Boa Vista/RR, transmitido por felino infectado (transmissão secundária), e um caso em Iracema/CE, por morcego (Desmodus rotundus), ambos pela variante 3. Já no de 2017, um caso ocorreu em Pernambuco, após agressão de um gato de rua infectado com a variante 3 , o que demonstra a importância dos animais domésticos como transmissores secundários da raiva. Os demais casos de raiva humana ocorreram devido a acidentes com cães, morcegos e primatas. Considerando o gato doméstico como um potencial transmissor da raiva humana, este estudo teve como objetivo descrever o perfil epidemiológico do paciente agredido por esse animal, bem como avaliar a distribuição temporal do atendimento antirrábico pósexposição, no município de Belo Horizonte (MG), no período de 2007 a 2016.

\section{MATERIAL E MÉTODOS}

Foi realizado um estudo observacional, retrospectivo e descritivo, a partir da análise exploratória das fichas do Atendimento Antirrábico Humano pós- exposição do Sistema de Informação de Agravos de Notificação Sinan. Esses dados foram cedidos pela Prefeitura Municipal de Belo Horizonte, envolvendo acidentes com gatos domésticos, no período de 01 de janeiro de 2007 a 31 de dezembro de 2016, de residentes e não residentes, notificados em Belo Horizonte/MG. Um banco de dados foi estruturado e adaptado para a realização do estudo, contendo 3.585 notificações de atendimentos antirrábicos humanos. Realizou-se uma análise da distribuição dos dados ao longo dos anos e uma análise descritiva dos acidentes envolvendo pacientes que receberam atendimento antirrábico pós-exposição.

Foram excluídas do banco de dados inicial 996 fichas de atendimento e obteve-se um banco de dados contendo 2.589 fichas, para as quais foram calculadas as frequências absolutas e relativas e geradas as tabelas e os gráficos em programa Excel 2013. Para análise das variáveis, foram utilizados os seguintes campos da ficha do Atendimento Antirrábico Humano: data da notificação, idade, sexo, raça ou cor, zona, data da exposição, tipo de exposição ao vírus, localização anatômica do ferimento, ferimento, tipo de ferimento. Para análise da idade dos pacientes atendidos, foi realizada uma estratificação por faixas etárias conforme Gomide Júnior (2013).

A avaliação do preenchimento das fichas de notificação do Sinan foi realizada de acordo com o dicionário de dados (Brasil, 2010; 2014). As distribuições das frequências entre as diferentes variáveis foram feitas pelo teste de qui-quadrado (Sampaio, 2007), utilizando-se o programa Stata 14.0. O presente estudo foi aprovado pelo CEP UFMG - Comitê de Ética em Pesquisa da UFMG, sob protocolo CAAE número: 62506616.1.0000.5149 e pelo CEP SMSA-PBH - Comitê de Ética em Pesquisa da Secretaria Municipal de Saúde da Prefeitura de Belo Horizonte, sob protocolo CAAE número: 62506616.1.3001.5140, no Sistema Plataforma Brasil, conforme resolução 466/12, que discorre a respeito das pesquisas envolvendo seres humanos. 


\section{RESULTADOS E DISCUSSÃO}

As notificações dos atendimentos antirrábicos humanos relacionados a acidentes com gatos domésticos representaram $13,4 \%$ do total de notificações, no período de 2007 a 2016, em Belo Horizonte. Esse resultado corrobora dados do Ministério da Saúde (Brasil, 2016), segundo o qual $11,7 \%$ das notificações da profilaxia antirrábica humana no Brasil ocorreram devido a agressões por gatos domésticos. Andrade (2014), no município de Araçatuba-SP, encontrou 10,4\% das notificações oriundas de acidentes com gatos. Abreu e Crizóstomo (2014), no município de Teresina-PI, encontraram $18 \%$ das notificações relacionadas a acidentes com gatos, e Matos et al. (2017), em Brasília-DF, encontraram $20,7 \%$ das notificações oriundas de acidentes ocorridos com gatos. Corrêa et al. (2014), em Maringá-PR, encontraram aproximadamente $5 \%$ das notificações oriundas de agressões por gatos.

Para a formação do banco de dados, foram excluídas $996(27,8 \%)$ fichas das 3.585 notificações do atendimento antirrábico humano pós-exposição, as quais apresentavam respostas, para algumas variáveis de interesse, em branco e/ou ignoradas, além de tratamentos préexposição. Cabral et al. (2018) observaram $15,3 \%$ de exclusão em seu banco de dados inicial de acidentes envolvendo cães, no município de Belo Horizonte/MG. A diferença encontrada pode ter ocorrido pelo fato de os gatos apresentarem menor importância epidemiológica relativa ao ciclo urbano da raiva, quando comparados com os cães. Sugere-se que o agravo envolvendo os cães teria maior visibilidade e cuidado no preenchimento das fichas de notificação. $\mathrm{O}$ preenchimento inadequado da ficha acarreta perdas de dados e informações que poderiam contribuir para o melhor conhecimento epidemiológico das agressões por gatos domésticos.

Em relação à distribuição temporal das notificações do atendimento antirrábico humano pós-exposição, observou-se que os anos de 2007 a 2014 foram responsáveis por $42,6 \%$ delas, e os anos de 2015 e 2016 por 57,4\% (Fig. 1).

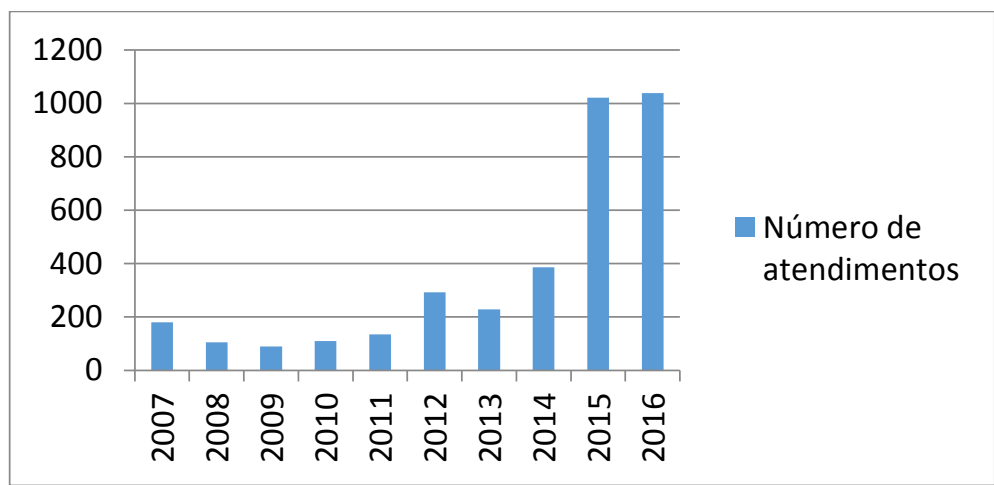

Figura 1. Distribuição dos atendimentos antirrábicos humanos pós-exposição em Belo Horizonte/MG, nos anos de 2007 a 2016.

Pode-se associar o crescimento da demanda por atendimento antirrábico ao aumento da população de gatos em Belo Horizonte, fenômeno que ocorre no Brasil e já ocorreu em outros países do mundo, como EUA, Reino Unido e China (Bernstein, 2007). De acordo com Carvalho (2018), a população de gatos domésticos em Belo Horizonte teve um crescimento expressivo de $197 \%$ nos anos de 2007 a 2017. Além disso, Carvalho (2018) observou que o abandono de gatos nas ruas faz com que a população de animais errantes se mantenha, havendo reposição de novos indivíduos após o recolhimento. Animais errantes, assim como os gatos semidomiciliados, contribuem para o crescimento populacional da espécie, o que propicia a aglomeração e a organização de colônias, principalmente espaços públicos, como parques, praças e universidades (Ramos, 2015).

Como consequências do aumento da população dessa espécie animal em áreas urbanas e rurais, aumenta-se o risco de transmissão de zoonoses, a predação da fauna silvestre e os maus-tratos (Nogales et al., 2004). Entre as zoonoses 
prevalentes no Brasil, em que o gato tem papel epidemiológico relevante, pode-se citar a raiva humana (em seu ciclo urbano e aéreo), a esporotricose e a toxoplasmose (Carvalho, 2018). De acordo com a PBH (Belo Horizonte, 2015), a principal unidade notificadora para profilaxia antirrábica do município, o Crie (Centro Referência em Imunobiológicos Especiais) não notificava diretamente no Sinan até meados de 2014, o que gerava baixos números de notificações nesse sistema. Portanto, a partir do momento em que o Crie começou a notificar diretamente no Sinan, houve um acréscimo no número de notificações nos anos de 2015 e 2016.
De acordo com a Tab. 1, 63,7\% das agressões por gatos ocorreram com pessoas do gênero feminino, no período analisado. Entre as faixas etárias, adultos entre 20 e 59 anos obtiveram o maior número de notificações, correspondendo a $57,3 \%$, seguidos de idosos, $16,9 \%$, e crianças de zero a 10 anos, $15,5 \%$. Jovens entre 11 e 19 anos foram os menos notificados, com 10,4\%. Gomide Júnior (2013), em Luiz Antônio-SP, observou $56,6 \%$ das notificações para homens e $41,1 \%$ para pessoas entre 20 e 59 anos. Abreu e Crizóstomo (2014) encontraram 53\% de notificações de pessoas do gênero masculino e $57 \%$ para faixa etária entre 20 e 59 anos (Tab. 1).

Tabela 1. Distribuição dos atendimentos antirrábicos humanos pós-exposição envolvendo acidentes com gatos, segundo faixa etária e gênero dos pacientes em Belo Horizonte-MG

\begin{tabular}{llll} 
Faixa etária & Feminino $\%$ & Masculino $\%$ & Total \\
\hline 0 a 10 anos & $215(8,3 \%)$ & $186(7,2 \%)$ & $401(15,5 \%)$ \\
11 a 19 anos & $152(5,9 \%)$ & $116(4,5 \%)$ & $268(10,4 \%)$ \\
20 a 59 anos & $969(37,4 \%)$ & $516(19,9 \%)$ & $1485(57,3 \%)$ \\
60 ou mais anos & $312(12,1 \%)$ & $123(4,8 \%)$ & $435(16,9 \%)$ \\
Total & $1648(63,7 \%)$ & $941(36,3 \%)$ & $2589(100 \%)$ \\
\hline
\end{tabular}

*Qui-quadrado valor de $\mathrm{P} \leq 0,000$

Observa-se que há uma associação entre idade e sexo, como mostrado pelo teste de qui-quadrado, com valor de $\mathrm{P} \leq 0,05$. Sugere-se que pessoas da faixa etária adultos entre 20 e 59 anos estejam mais expostas a agressões por gatos domésticos devido às atividades diárias. Pode-se mencionar tanto as atividades laborais, como, por exemplo, médicos veterinários, profissionais banhistas de comércio pet, agentes de saúde e de endemias, agentes de correios, quanto as atividades nos lares que envolvem o cuidado com animais domésticos. A faixa etária entre 20 e 59 anos do gênero feminino representou $37,4 \%$; o gênero masculino entre 20 e 59 anos, 19,9\% (Tab. 1). Sugere-se que a alta frequência encontrada no presente estudo, para mulheres adultas agredidas por gatos, pode estar relacionada à maior afinidade com esses animais em comparação aos homens.

Entre os benefícios que se pode citar relativos à presença de animais na vida das pessoas, a companhia é de grande relevância. Cavalos, cães e gatos são referidos, na sociedade atual, como "animais de companhia", por estabelecerem vínculos emocionais recíprocos e fortes com os humanos (Faraco, 2008). Segundo Beaver (2003), para as mulheres, os gatos podem substituir o afeto de crianças e, ao se tornarem viúvas, ajudando a suprir, dessa forma, necessidades emocionais humanas. Becker (2003) afirma que é crescente o número de pessoas, especialmente mulheres, que vivem sozinhas e que fazem dos cães e gatos suas companhias. Entretanto, de acordo com Curtis (2008), interpretações equivocadas por parte dos tutores dos gatos em relação ao comportamento dos felinos podem ocorrer, e a agressividade é um dos principais problemas relatados, sendo considerado, muitas vezes, um comportamento natural para a espécie. A agressividade a humanos pode ocorrer principalmente por brincadeiras, medo, comportamento predatório, agressão induzida por afagos, status, bem como redirecionada por dor ou pela agressividade de gatas com filhotes.

Entre as 2.589 fichas de atendimento, observouse que, em $88,7 \%$ delas, os pacientes eram residentes em áreas urbanas, resultado semelhante ao encontrado por Gomide Júnior (2013), que observou 92\% dos pacientes residentes em área urbana. Em relação à raça/cor dos pacientes, 26,1\% eram de etnia branca, $16,8 \%$ eram pardos e 52,8\% não apresentavam resposta. Abreu e Crizóstomo (2014) 
encontraram $94 \%$ de registros para cor parda e $5 \%$ de registros para cor branca. Corrêa et al. (2014) observaram $74,4 \%$ de registros para cor branca e $15,6 \%$ para cor parda. Sugere-se que essa diferença encontrada em relação à cor de pele dos pacientes provavelmente se relacione à região do país em que a análise foi realizada. Em relação ao intervalo de tempo entre suposta exposição ao vírus rábico e a busca por atendimento profilático, observou-se que, em $31,7 \%$ das notificações, a busca por tratamento antirrábico pós-exposição foi realizada com menos de 24 horas de intervalo de tempo entre a suposta exposição ao vírus rábico e o atendimento inicial antirrábico humano pósexposição, e 33,9\% delas com um dia de intervalo.

Gomide Júnior (2013) encontrou 86,8\% de notificações realizadas com menos de $24 \mathrm{~h}$ entre o momento da exposição e o da busca por tratamento profilático. Matos et al. (2017) observaram que $59,1 \%$ dos pacientes buscaram atendimento com menos de 24 horas de intervalo entre exposição e busca por atendimento. É importante ressaltar que Gomide Júnior (2013) e Matos et al. (2017) analisaram, em seus trabalhos, notificações do atendimento antirrábico pós-exposição humano, em que o cão era a espécie predominante em ambos os trabalhos. Sugere-se que a diferença entre os resultados observados nos estudos com cães em comparação com os atendimentos antirrábicos humanos ocasionados com acidentes com gatos pode ter ocorrido devido ao fato de a percepção de risco em relação à exposição ao vírus rábico ser menor quando o animal agressor é o gato, e não o cão, já que o cão é a principal espécie transmissora de raiva ao homem em diversas regiões do mundo. Esse fato demonstra a necessidade de melhoria no nível de instrução das pessoas em relação à busca de atendimento antirrábico, para que ele seja imediato, ou seja, em menos de 24 horas, independentemente da espécie envolvida no acidente.

De acordo com as Normas Técnicas de Profilaxia da Raiva Humana (Brasil, 2014), o tratamento pós-exposição da raiva humana deve ser realizado o mais precocemente possível. Este deve se iniciar pela lavagem imediata da ferida no local da agressão e pela busca imediata de socorro em uma unidade de saúde que seja apta a realizar a profilaxia pós-exposição da raiva humana. Sabe-se da circulação de morcegos positivos para raiva em centros urbanos do Brasil; assim, existe um risco de exposição de animais domésticos, incluindo os gatos, principalmente por variantes antigênicas do vírus rábico típicas de morcego. Em Belo Horizonte/MG, desde 1989 não se registram casos de raiva canina e felina (Belo Horizonte, 2013) e a circulação do vírus da raiva é mantida sob vigilância pelo Laboratório de Morcegos Urbanos da Secretaria Municipal de Saúde (SMSA) e pelas gerências de epidemiologia das regionais. A vigilância é feita desde 2004. No ano de 2018, foram diagnosticados nove morcegos positivos para doença na capital (Belo Horizonte, 2018).

Em relação à caracterização dos atendimentos segundo o tipo de exposição, a localização anatômica das lesões, o número de ferimentos e a profundidade dos ferimentos, observa-se, na Tab. 2, que, entre as 2.589 fichas de atendimento, o tipo de exposição ao vírus rábico mais frequente foi mordedura de gatos em 75,6\% delas, seguida de agressões por arranhadura em 23,2\%. Para determinação das características da lesão, foi necessário escolher a mais relevante para a transmissão do vírus rábico, quando havia mais de uma lesão (Tab. 2).

Cabral et al. (2018), ao analisarem um banco de dados associado a acidentes com cães, encontraram mordedura em $93,0 \%$ deles e, em $5,2 \%$, arranhadura. A diferença encontrada em relação à frequência de arranhadura entre cão e gato como forma de exposição ao vírus rábico provavelmente ocorreu devido às diferenças anatômicas e funcionais da garra entre essas espécies. Ao contrário dos cães, os gatos utilizam suas garras para ataque e defesa e para o contato inicial com sua presa (König e Liebich, 2016). Nos gatos, as garras apresentam-se fortemente curvas, projetando-se até formarem uma ponta afiada e penetrante com arquitetura retrátil, o que reduz a possibilidade de desgaste, mantendo-as finas e cortantes (König e Liebich, 2016). Nos cães, as garras não retráteis ficam expostas, com a finalidade de aumentar a tração com o solo nas corridas (Hildebrand e Goslow, 2006). 
Tabela 2. Caracterização dos atendimentos antirrábicos humanos pós-exposição, segundo o tipo de exposição, a localização, o número de ferimentos e o tipo de ferimento, em Belo Horizonte-MG

\begin{tabular}{ll}
\hline Número de agravos n $(\%)$ \\
\hline Tipo de exposição & \\
\hline Arranhadura & $600(23,2 \%)$ \\
Contato indireto & $22(0,8 \%)$ \\
Lambedura & $11(0,4 \%)$ \\
Mordedura & $1956(75,6 \%)$ \\
Total & $2589(100 \%)$ \\
Localização & \\
Cabeça/pescoço/face & $170(6,6 \%)$ \\
Mãos/pés & $1610(62,2 \%)$ \\
Membros inferiores & $324(12,5 \%)$ \\
Membros superiores & $409(15,8 \%)$ \\
Mucosa & $25(1,0 \%)$ \\
Tronco & $51(2,0 \%)$ \\
Total & $2589(100 \%)$ \\
Ferimento & \\
Múltiplo & $1293(49,9 \%)$ \\
Único & $1296(50,1 \%)$ \\
Total & $2589(100 \%)$ \\
Tipo de ferimento & \\
Dilacerante & $66(2,5 \%)$ \\
Profundo & $981(37,9 \%)$ \\
Superficial & $1542(59,6 \%)$ \\
Total & $2589(100 \%)$ \\
\hline
\end{tabular}

Quanto à localização anatômica das lesões, mãos e pés representaram $62,2 \%$ das notificações, seguidos de membros superiores em 15,8\%, sendo essas as regiões acometidas com maior frequência. $\mathrm{O}$ presente estudo divergiu parcialmente de Cabral et al. (2018), que encontraram, como regiões anatômicas mais acometidas por cães, os membros inferiores $(35,5 \%)$, seguidos de mãos/pés, em 33,1\% dos casos notificados. Corrêa et al. (2014) encontraram $30 \%$ em membros inferiores e $39,7 \%$ em mãos e pés, sendo o cão a espécie encontrada com maior frequência no estudo. A diferença observada entre trabalhos nos quais a espécie animal foi o cão e o presente estudo permite sugerir que os gatos domésticos causam lesões com maior frequência em regiões anatômicas que caracterizam acidentes graves para exposição ao vírus rábico, segundo o protocolo do Ministério da Saúde.

Quanto ao fato de o ferimento ser único ou múltiplo, os resultados foram homogêneos, sendo 50,1\% únicos e 49,9\% múltiplos. Andrade
(2014), Abreu e Crizóstomo (2014) e Cabral et al. (2018) encontraram ferimentos únicos predominantes em suas pesquisas variando entre $57 \%$ e $65,5 \%$, sendo o cão a espécie encontrada com maior frequência nos estudos. Sugere-se que gatos possam causar acidentes mais graves quando comparados com cães, já que se tem mais uma porta de entrada para o vírus rábico e maior dose infectante.

Quanto ao tipo de ferimento, as lesões superficiais foram predominantes em $59,6 \%$ das notificações, corroborando parcialmente o trabalho de Andrade (2014), que encontrou $53,3 \%$, e o de Cabral et al. (2018), que encontraram $65,8 \%$ de lesões superficiais em atendimentos em que o cão era a espécie predominante e única, respectivamente. Corrêa et al. (2014) observaram, em um banco com acidentes envolvendo gatos, $56,8 \%$ de ferimentos superficiais, $36,8 \%$ profundos e $6,4 \%$ dilacerantes. No presente estudo, ferimentos dilacerantes e profundos representaram $40,4 \%$.

Em relação à localização anatômica das lesões segundo faixa etária dos pacientes (Tab. 3), observou-se que, em todas as faixas etárias, a região anatômica atingida com maior frequência foi mãos/pés, seguida dos membros superiores. Apenas em idosos, a segunda região mais afetada foi membros inferiores, representando $3,2 \%$.

A faixa etária de crianças de zero a 10 anos representou 15,5\% das notificações. Destaca-se, dentro dessa faixa etária, o acometimento das regiões anatômicas mãos/pés, com 146 notificações, e cabeça/pescoço/face (88), as quais totalizaram 234 notificações, representando $58,35 \%$ das notificações em crianças de zero a 10 anos. Essas regiões são consideradas de grande relevância para a infecção do vírus rábico devido ao alto grau de inervação e à proximidade com o sistema nervoso central. Sugere-se que essa alta frequência esteja relacionada às agressões defensivas, em que o animal, após ser provocado, uma vez que a criança não tem percepção de risco, reage em momento de estresse, causando lesões nas mãos e cabeça/pescoço/face, que são as regiões do corpo da criança mais próximas ao animal, diferentemente do cão, que, em geral, ataca as pessoas em maior frequência em membros inferiores (Cabral et al., 2018). 
Tabela 3. Caracterização dos atendimentos iniciais da profilaxia antirrábica humana pós-exposição, segundo localização anatômica das lesões e faixa etária dos pacientes, em Belo Horizonte-MG

\begin{tabular}{|c|c|c|c|c|c|}
\hline \multirow[b]{2}{*}{ Localização } & \multicolumn{5}{|l|}{ Faixa etária } \\
\hline & $\begin{array}{l}0 \text { a } 10 \text { anos } \\
\text { n (\%) }\end{array}$ & $\begin{array}{l}11 \text { a } 19 \text { anos } \\
\text { n (\%) }\end{array}$ & $\begin{array}{l}20 \text { a } 59 \text { anos } \\
\mathrm{n}(\%)\end{array}$ & $\begin{array}{l}60 \text { ou mais anos } \\
\mathrm{n}(\%)\end{array}$ & Total n(\%) \\
\hline $\begin{array}{l}\text { Cabeça/ } \\
\text { pescoço }\end{array}$ & $88(3,4 \%)$ & $24(0,9 \%)$ & $51(2,0 \%)$ & $7(0,3 \%)$ & $170(6,6 \%)$ \\
\hline Mãos/ pés & $146(5,6 \%)$ & $158(6,1 \%)$ & $1.035(40,0 \%)$ & $271(10,5 \%)$ & $1610(62,2 \%)$ \\
\hline $\begin{array}{l}\text { Membros } \\
\text { inferiores }\end{array}$ & $56(2,2 \%)$ & $25(1,0 \%)$ & $160(6,2 \%)$ & $83(3,2 \%)$ & $324(12,5 \%)$ \\
\hline $\begin{array}{l}\text { Membros } \\
\text { superiores }\end{array}$ & $88(3,4 \%)$ & $48(1,9 \%)$ & $207(8,0 \%)$ & $66(2,5 \%)$ & $409(15,8 \%)$ \\
\hline Mucosa & $11(0,4 \%)$ & $3(0,1 \%)$ & $9(0,3 \%)$ & $2(0,1 \%)$ & $25(1,0 \%)$ \\
\hline Tronco & $12(0,5 \%)$ & $10(0,4 \%)$ & $23(0,9 \%)$ & $6(0,2 \%)$ & $51(2,0 \%)$ \\
\hline Total & $401(15,5)$ & $268(10,4 \%)$ & $1485(57,4 \%)$ & $435(16,8 \%)$ & $2589(100 \%)$ \\
\hline
\end{tabular}

\section{CONCLUSÕES}

Os resultados permitiram conhecer o perfil epidemiológico do paciente que busca por atendimento antirrábico humano após acidente associado a gatos domésticos, em Belo Horizonte. Houve predominância de mulheres adultas, residentes de área urbana, de etnia branca. Mordedura e arranhadura foram as formas de exposição ao vírus rábico mais frequentes. Observou-se alta frequência de lesões em regiões anatômicas, que caracterizaram acidentes graves para exposição ao vírus rábico, sendo predominantes lesões em mãos/pés. A frequência encontrada para o intervalo de tempo inferior a 24 horas após a exposição ao vírus rábico foi baixa, indicando necessidade de adoção de medidas socioeducativas junto à população para melhores esclarecimentos sobre o risco de acidentes envolvendo gatos, principalmente em regiões em que o vírus rábico circula em populações de morcegos, como é o caso de Belo Horizonte. Melhorias no preenchimento das fichas de notificação do Sinan são necessárias, visto que as análises dos bancos de dados são fundamentais para maior eficácia na gestão do serviço de vigilância da doença. Conhecer o papel do gato como potencial transmissor da raiva em ambientes urbanos se faz necessário, visto que pouco se publica a respeito.

\section{AGRADECIMENTOS}

À Fundação de Amparo à Pesquisa do Estado de Minas Gerais (Fapemig).

\section{REFERÊNCIAS}

ABREU, N.A.C.; CRIZÓSTOMO, C.D. Perfil epidemiológico do cliente no atendimento antirrábico humano em Teresina - PI. Rev. Interdisc., v.7, p103-111, 2014.

ALMEIDA, M.F.; ROSA, A.R.; SODRÉ, M.M. et al. Fauna de morcegos (Mammalia, Chiroptera) e a ocorrência de vírus da raiva na cidade de São Paulo, Brasil. Vet. Zootec. v.22, p.89-100, 2015.

ANDRADE, B.M.F.C. Avaliação da indicação do tratamento antirrábico humano em relação a situação epidemiológica da doença. 2014. 58f. Dissertação (Mestrado em Medicina Veterinária) - Faculdade de Medicina Veterinária. Universidade Estadual Paulista, Araçatuba, SP.

BEAVER, B.V. Feline behavior: a guide for veterinarians. 2.ed. Philadelphia: Elsevier Science, 2003.

BECKER, M. O poder curativo dos bichos: como aproveitar a incrível capacidade dos bichos de manter as pessoas felizes e saudáveis. Rio de Janeiro: Bertrande Brasil, 2003. 322p. 
BELO HORIZONTE. Prefeitura de Belo Horizonte. Boletim de Vigilância em Saúde. 2015. Ano 5. Disponível em: <https://prefeitura.pbh.gov.br/sites/default/files/e strutura-de-governo/saude/2018/publicacaoes-davigilancia-em-saude/boletim-raiva-2015web.pdf>. Acessado em 17 jan. 2019.

BELO HORIZONTE. Prefeitura de Belo Horizonte. Notícias. Monitoramento de morcegos e estratégia de controle da raiva em Belo Horizonte. 2018. Disponível em: $<$ https://prefeitura.pbh.gov.br/noticias/monitora mento-de-morcegos-e-estrategia-no-controle-daraiva-em-belo-horizonte>. Acessado em: 17 de jan. de 2019.

BELO HORIZONTE. Prefeitura de Belo Horizonte. Boletim da Vigilância em Saúde dezembro 2012. Ano 2013. Disponível em:<https://prefeitura.pbh.gov.br/sites/default/fil es/estrutura-de

governo/saude/2018/publicacaoes-da-vigilanciaem-saude/boletim_GVSI2_12.pdf> Acessado em: 13 jan. 2019.

BERNSTEIN, P.L. The human-cat relationship. In: ROCHLITZ, I. The welfare of cats. Cambridge: Springer, 2007. p.47-91.

BRASIL. Ministério da Saúde. Nota Informativa. $2017 . \quad$ Disponível em: <http://portalarquivos.saude.gov.br/images/pdf/2 017/agosto/04/Nota-Informativa-N-

26_SEI_2017_CGPNI_DEVIT_SVS_MS.pdf>

Acessado em: 10 dez. 2017.

BRASIL. Ministério da Saúde. Secretaria de Vigilância em Saúde. Bol. Epidemiol., v.47, n.30. Brasilia: 2016. Disponível em: <http://portalarquivos.saude.gov.br/images/pdf/2 016/julho/29/2016-010.pdf>. Acessado em: 22 ago. 2017.

BRASIL. Ministério da Saúde. Secretaria de Vigilância em Saúde. Departamento de Vigilância Epidemiológica. Normas técnicas de profilaxia da raiva humana. Brasil, Brasília: Ministério da saúde; 2014. 60p.
BRASIL. Ministério da Saúde. Sistema de informação de agravos de notificação. Atendimento antirrábico. Dicionário de dados Versão 5.0, 2014. Disponível em: <http://portalsinan.saude.gov.br/images/documen tos/Agravos/Atendimento\%20Anti-

rabico/DIC_DADOS_anti_rabico_v5.1.pdf>. Acessado em 22 de ago. 2017.

BRASIL. Ministério da Saúde. Sistema de informação de agravos de notificação. Dicionário de dados. Versão 5.0. 2010. Disponível em: <http://portalsinan.saude.gov.br/images/documen tos/Agravos/NINDIV/DIC_DADOS_Notificacao _Individual_v5.pdf $>$. Acessado em 22 de ago. 2017.

BRASIL. Ministério da Saúde. Situação epidemiológica da raiva. Disponível em: <http://portalms.saude.gov.br/saude-de-az/raiva/situacao-epidemiologica $>$ Acessado em: 10 de jan. 2018.

BUNN, T.O. Cat rabies. In: BAER, G.M. The natural history of rabies. 2.ed. New York. CRC Press, 1991. p.379-388.

CABRAL, K.; OLIVEIRA, M.A.; DINIZ, S.A.; HADDAD, J.P.A. et al. Avaliação do atendimento antirrábico humano pós-exposição, associado a acidentes com cães. Arq. Bras. Med. Vet. Zootec., v.70, p.682-688, 2018.

CARVALHO, P.C.F.B. Caracterização populacional e descrição do manejo de gatos errantes no Parque Municipal Américo Renné Giannetti, Belo Horizonte, MG. 2018. 86f. Dissertação (Mestrado em Medicina Veterinária) - Escola de Veterinária, Universidade Federal de Minas Gerais, Belo Horizonte, MG.

CORRÊA, M.A.; MARTINS, N.S.; CHAGAS, E.N.; FERREIRA E.B. Caracterização dos casos de atendimentos anti-rábicos humanos na cidade de Maringá, PR. Sigmae, v.2, p.16-24, 2014.

CURTIS, T.M. Human-directed aggression in the cat. Vet. Clin. N. Am. Small Anim. Pract., v.38, p.1131-1143, 2008 .

FARACO, C.B. Interação humano-animal. Ciênc. Vet. Trop., v.11, p.31-35, 2008. 
GENARO, G. Gato doméstico: futuro desafio para controle da raiva em áreas urbanas? Pesqui. Vet. Bras., v.30, p.186-189, 2010.

GOMIDE JUNIOR, M.H. Profilaxia da raiva humana em Luís Antônio, SP, Brasil: características das ocorrências e atenção médica prestada aos pacientes. 2013. 94f. Dissertação (Mestrado em Saúde da Comunidade) Faculdade de Medicina de Ribeirão Preto, Universidade de São Paulo, Ribeirão Preto, SP.

HILDEBRAND, M.; GOSLOW, G. Análise da estrutura dos vertebrados. 2.ed. São Paulo: Atheneo, 2006. 637p.

KÖNIG, H.; LIEBICH, E. Anatomia dos animais domésticos: texto e atlas colorido. 6.ed. Porto Alegre: Artmed, 2016. 804p.

MATOS, J.C.; MAFRA, C.R.; ANDRETTA, A.G.M.; ALVES, L.R. Acompanhamento antirrábico humano e consequente adesão à profilaxia pós-exposição. Rev. Enfem., v.11, Supl.3, p.1451-1457, 2017. Disponível em: <http://www.revista.ufpe.br/revistaenfermagem/i ndex.pLhp/revista/article/view/9964/pdf_2789>. Acessado em: 15 jul. 2017.

NOGALES, M.; MARTÍN, A.; TERSHY, B.R. et al. A review of feral cat eradication on islands. Conserv. Biol., v.18, p.310-319, 2004.

RAMOS, I.F.B. Manejo populacional de gatos (Felis silvestris catus): uma abordagem comportamental. 2015. 101f. Dissertação (Mestrado em Ciência) - Faculdade de Filosofia, Ciências e Letras de Ribeirão Preto, Universidade de São Paulo, Ribeirão Preto, SP.

SAMPAIO, I.B.M. Estatística aplicada à experimentação animal. 3.ed. Belo Horizonte: Fundação de Estudo e Pesquisa em Medicina Veterinária e Zootecnia, 2007. 264p.

WADA, M.Y.; ROCHA, S.M.; MAIAELKHOURY, A.N.S. Situação da raiva no Brasil, 2000 a 2009. Epidemol. Serv. Saúde, v.20, p.509-518. 2011. 